\title{
Electron band structure and properties of disordered semiconductor compound alloys
}

\author{
D. Alexandrov ${ }^{1}$, K. S. A. Butcher ${ }^{2} \&$ T. L. Tansley ${ }^{2}$ \\ ${ }^{I}$ Department of Electrical Engineering, Lakehead University, Canada \\ ${ }^{2}$ Physics Department, Macquarie University, Australia
}

\begin{abstract}
A new metric system called the electron metric system, having a basic metric constant, is introduced. The connection between the electron metric system and the external metric system is defined. The symmetry relationships of the multinary semiconductor compound alloys are defined according to the electron metric system. The basic metric constant is found on the basis of a diatomic tetrahedral cell. The electron wave vector in the new system is found and the electron energy states are determined. Correlation is shown between the electron energy and the electron wave vector in the multinary crystal. The LCAO electron band structures of $\operatorname{In}_{\mathrm{x}} \mathrm{Al}_{1-\mathrm{x}} \mathrm{N}$ are presented. The phenomenon tunnel optical absorption is investigated in $\operatorname{In}_{x} \mathrm{Al}_{1-\mathrm{x}} \mathrm{N}$, in $\operatorname{In}_{\mathrm{x}} \mathrm{Ga}_{1-\mathrm{x}} \mathrm{N}$, in $\operatorname{InN}$ containing oxygen and in non-stoichiometric InN. It is found the optical absorption edges begin in energies much lower than the energy band gaps due to this phenomenon. Existence of excitons of the structure is shown in these semiconductors and it is found that the peaks of the PL spectra correspond to annihilation energies of these excitons.
\end{abstract}

Keywords: semiconductor compound alloys, optical properties.

\section{Introduction}

The relatively recent observation of $0.7 \mathrm{eV}$ photoluminescence for $\mathrm{InN}$, and of absorption features near this energy have been the subject of a number of recent papers [1-3]. It has been proposed that the low energy features indicate a $0.7 \mathrm{eV}$ band-gap. However, the material had long been held to have a much higher band-gap of $1.9 \mathrm{eV}$. The large difference between these values is not presently understood. The Moss-Burstein effect does not explain the variation seen for 
material of low carrier concentration, and Vegard's law indicates that oxygen levels in the higher band-gap material are insufficient to account for the difference [4]. Sample inhomogeneity offers a strong possible explanation. The grown conditions are known to form non-stoichiometric indium nitride during the growth of nitride films. One now seeks to investigate the possibility that these low energy features arise as growth artifacts, due to an alloy formed by non-stoichiometric InN containing both single In substitutions on $\mathrm{N}$ sites and single $\mathrm{N}$ substitutions on In sites.

A new metric system called the electron metric system is introduced in this paper. The connection between the electron metric system and the external metric system is defined. The symmetry relationships of the multinary semiconductor compound alloys are defined according to the electron metric system. The electron wave vector in the electron metric system is found and the electron energy states are determined. Correlation is shown between the electron energy and the electron wave vector in the multinary crystal. LCAO electron band structure of $\operatorname{In}_{\mathrm{x}} \mathrm{Al}_{1-\mathrm{x}} \mathrm{N}$ is presented. The phenomenon tunnel optical absorption is investigated in $\operatorname{In}_{x} \mathrm{Al}_{1-\mathrm{x}} \mathrm{N}$, in $\operatorname{In}_{\mathrm{x}} \mathrm{Ga}_{1-\mathrm{x}} \mathrm{N}$, in $\mathrm{InN}$ containing oxygen and in non-stoichiometric InN. It is found the optical absorption edges in these semiconductors begin in energies much lower than the energy band gaps due to this phenomenon. Existence of excitons of the structure is shown in these semiconductors and it is found that the peaks of the PL spectra correspond to annihilation energies of these excitons.

\section{Metric system and symmetries in multinary crystal}

The existing metric system in the solid state physics is defined on the basis of positions of the ions building the crystal lattice. One can call it the metric system of the external observer or simpler external metric system. It does not account for the electron interactions. We will define the metric system in the multinary crystal in terms of electron interaction because it is the basis of the determination of the electronic and optical properties of solid state. One can call it the electron metric system. The definition will be done on the basis of the following assumptions:

i) Every quasi-elementary cell (defined in [5] for multinary crystal) is built by points, which are identical with the corresponding points in all other quasi-elementary cells of the multinary crystal in term of electron propagator (The quasi-elementary cell doesn't contain any other points.);

ii) The quasi-elementary cell is electro-neutral;

iii) The atomic substitutions in multinary crystal save the valences of the corresponding atoms;

iv) The electrical charges are of point type and they are concentrated exclusively in the nodes of the crystal lattice;

v) One electron approximation has place.

Weyl's metric system will be used $[6,7]$, i.e. the length is defined by 


$$
l=l_{0} \exp \left(\alpha \int \Phi_{i} d x_{i}\right)
$$

where $l_{0}$ is metric constant, $\alpha$ is proportional factor, $\Phi_{i}$ is component of the electric field, and $x_{i}$ is the coordinate in the external metric system $(i=1,2,3)$. The integration takes place between two points of the external system and $l$ is the corresponding distance in the electron metric system. One will define the metric length in the multinary crystal in term of change of electron energy when the electron moves in the electrical field of the crystal lattice formed by the electrical fields of the nuclei, i.e.

$$
l=l_{0} \exp \left(\alpha \int \epsilon_{i} d x_{i}\right)
$$

where $\epsilon_{i}=C_{i}\left(x_{i}\right)$ is the corresponding component of the electrical field strength. The coordinate $l_{i}(i=1,2,3)$ in the electron metric system can be defined using (2).

The integration in (2) between two nodes of the crystal lattice having equal electron charges is equal to zero, i.e. $l=l_{0}$. Using this result one will define $l_{0}$ to be the distance in the electron metric system between nearest neighbouring atoms of the crystal lattice having equal electron charges. Let us consider that we have tetrahedral quasi-elementary cell of a multinary semiconductor compound alloy and that this cell is built by two sorts of nuclei - cationic and anionic. Also let us consider at this point that the cationic sub-lattice is built by atoms of one chemical element, and to consider the same for anionic sub-lattice (however both cationic element and anionic element are different atoms). Due to the distribution of the valence electrons the cationic atom has charge $+|Z|$, and the charge of the anionic atom is $-|Z|$. According to the assumption iv) given above these charges are concentrated exclusively in the nodes of the corresponding sub-lattices. The tetrahedral quasi-elementary cell contains cationic atom having charge $+|\mathrm{Z}|$ and anionic atom having charge $-|Z|$. The determination of the metric constant $l_{0}$ for this tetrahedral cell will be done and one-electron approximation will be considered (Fig.1). (Only part of the diatomic tetrahedral cell is given in Fig.1. However this part is enough to represent the interactions and the corresponding lengths due to the symmetry of the tetrahedral cell. The electro-neutrality of the tetrahedral cell is saved.)

The one-electron Schrödinger equation is given by

$$
\begin{gathered}
{\left[-\hbar^{2} \Delta / 2 m+e^{2}\left(|\mathrm{Z}|^{2} /\left(4 r_{A B}\right)-|\mathrm{Z}|^{2} /\left(2 r_{A C}\right)-|\mathrm{Z}|^{2} /\left(2 r_{B C}\right)-|\mathrm{Z}| /\left(2 r_{A}\right)-|\mathrm{Z}| /\left(2 r_{B}\right)\right.\right.} \\
\left.\left.+|\mathrm{Z}| / r_{C}\right)\right] \psi=\mathrm{E} \psi
\end{gathered}
$$

where $e$ is electron charge, $m$ is electron mass, $\psi$ is wave function in one-electron approximation, and $\mathrm{E}$ is electron energy. This equation is invariant in term of the metric system. Let's consider that the electron metric system takes place, i.e.

$$
r_{A B}=l_{0}
$$

Because the following equality is valid 


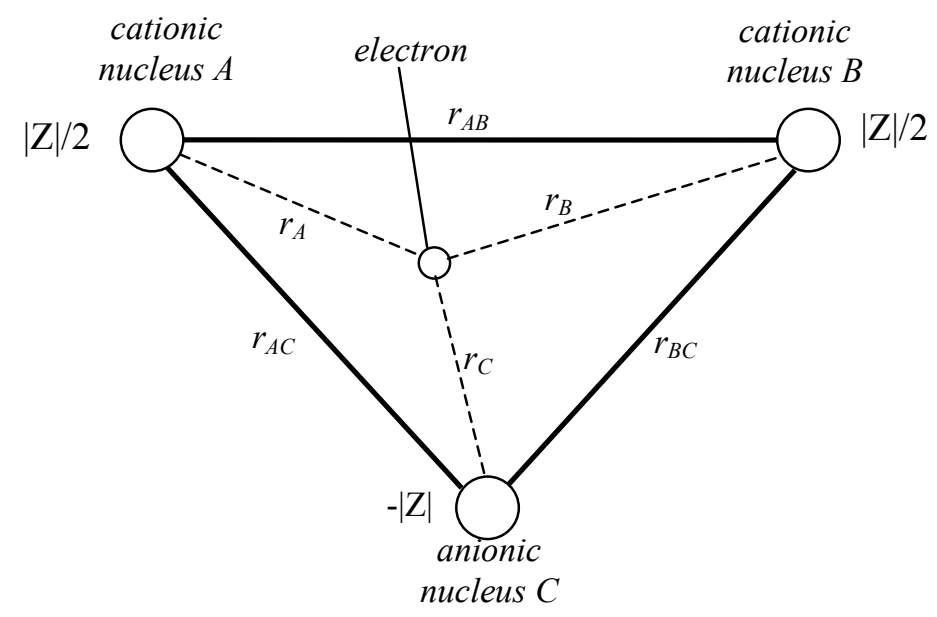

Figure 1: $\quad$ Part of the tetrahedral cell containing all possible distances.

$$
\begin{aligned}
& \xi_{B} \\
& \xi_{A} \\
& \xi_{A}
\end{aligned} \boldsymbol{\xi}=0
$$

where $\xi_{A}$ and $\xi_{B}$ are the positions of the atoms $A$ and $B$ in the external metric system, and the integration in (4) takes place in the external metric system as well. Let's consider the positions of the electron and of the atom $C$ in the external metric system to be $\xi_{e}$ and $\xi_{C}$ respectively. One has found

$$
r_{A C}=l_{0} \exp \left(\alpha \int_{\xi_{A}}^{\xi_{C}} \boldsymbol{\epsilon} d \xi\right)=l_{0} \exp (-3 \alpha e|\mathrm{Z}| / 2)
$$

Using (4) and (5) one has found

$$
r_{B C}=l_{0} \exp (3 \alpha e|\mathrm{Z}| / 2)
$$

Let's designate

$$
\int_{\xi_{A}}^{\xi_{e}} \epsilon d \xi=\beta
$$

Using this designation and expressions (4) and (5) one has found

$$
\begin{array}{cc}
r_{A}=l_{0} \exp (\alpha \beta) \\
r_{B}=l_{0} \exp (-\alpha \beta) \\
r_{C}=l_{0} \exp (-\alpha \beta) \exp (-3 \alpha e|\mathrm{Z}| / 2)
\end{array}
$$


Considering the expressions for the distances found above the Schrödinger equation becomes

$$
\begin{gathered}
\left\{-\hbar^{2} \Delta / 2 m+e^{2}\left[|\mathrm{Z}|^{2} /\left(4 l_{0}\right)-|\mathrm{Z}|^{2} /\left(2 l_{0} \exp (-3 \alpha e|\mathrm{Z}| / 2)\right)-|\mathrm{Z}|^{2} /\left(2 l_{0} \exp (3 \alpha e|\mathrm{Z}| / 2)\right)\right.\right. \\
\left.\left.-|\mathrm{Z}| /\left(2 l_{0} \exp (\alpha \beta)\right)-|\mathrm{Z}| /\left(2 l_{0} \exp (-\alpha \beta)\right)+|\mathrm{Z}| /\left(l_{0} \exp (-\alpha \beta) \exp (-3 \alpha e|\mathrm{Z}| / 2)\right)\right]\right\} \\
=\mathrm{E} \psi
\end{gathered}
$$

The metric constant $l_{0}$ is found as solution of (6) in the electron metric system assuming that $\psi$ is ortho-normal wave function

$$
\begin{gathered}
l_{0}=e^{2} /\left(\mathrm{E}_{\min }-\mathrm{H}_{0}\right)\left[\left(|\mathrm{Z}|^{2} / 4-|\mathrm{Z}|^{2} /(2 \exp (-3 \alpha e|\mathrm{Z}| / 2))-|\mathrm{Z}|^{2} /(2 \exp (3 \alpha e|\mathrm{Z}| / 2))\right.\right. \\
\left.-|\mathrm{Z}| \mathrm{H}_{-\beta} / 2-|\mathrm{Z}| \mathrm{H}_{\beta} / 2+|\mathrm{Z}| \mathrm{H}_{\beta} /(\exp (-3 \alpha e|\mathrm{Z}| / 2))\right]
\end{gathered}
$$

Where the matrix elements $\mathrm{H}_{0}, \mathrm{H}_{-\beta}$ and $\mathrm{H}_{\beta}$ are as follows

$$
\begin{gathered}
\mathrm{H}_{0}=\left\langle\psi\left|-\hbar^{2} \Delta / 2 m\right| \psi>\right. \\
\mathrm{H}_{-\beta}=\langle\psi|\exp (-\alpha \beta)| \psi>
\end{gathered}
$$

and

$$
\mathrm{H}_{\beta}=<\psi|\exp (\alpha \beta)| \psi>
$$

It is important to mention that integration for finding $\beta$ has a place in the external metric system, but the matrix elements are determined in the electron metric system. $\beta$ has continuous values within the tetrahedral cell and these values are equivalent for all tetrahedral cells having equal $|Z|$, i.e. the matrix elements $\mathrm{H}_{-\beta}$ and $\mathrm{H}_{\beta}$ depend only on $|\mathrm{Z}| . \mathrm{E}_{\min }$ is the minimum of the electron energy in tetrahedral cell having $|\mathrm{Z}|$. The authors believe there are other methods for determination of the metric constant $l_{0}$.

The distances between two nearest neighbouring cationic is $l_{0}$, also the distances between two nearest neighbouring anionic is $l_{0}$ as well.

Important conclusions can be made:

i) Tetrahedral cells containing two atoms and having the same values of $|\mathrm{Z}|$ have equal $l_{0}$ or in a multinary semiconductor compound alloy the different quasielementary tetrahedral cells containing two atoms and having equal values of $|\mathrm{Z}|$ have equal values of $l_{0}$, i.e. the lengths of the tetrahedral edges are equal in the electron metric system.

ii) The electron wave function $\psi(l)$ and the potential function $\mathrm{U}(\boldsymbol{l})$ of the multinary crystal have symmetry in the electron metric system that is the same as the symmetries of both the electron wave functions $\psi(x)$ and the potential functions $\mathrm{U}(\boldsymbol{x})$ of the binary constituents in the external metric system if $|\mathrm{Z}|$ remains constant for every quasi-elementary tetrahedral cell. (The binary constituents are building the multinary crystal.)

The binary alloys InN, GaN and AlN have values of $|\mathrm{Z}|-1.56,1.48$ and 1.36 respectively. (The calculations are performed on the basis of the polarities of these alloys given in [8]). The average value is $\left|Z_{\mathrm{av}}\right|=1.47$. It means that it can 
be considered that $|\mathrm{Z}|=1.47$ for the quasi-elementary tetrahedral cells of $\operatorname{In}_{x} \mathrm{Ga}_{1-x} \mathrm{~N}$, of $\operatorname{In}_{x} \mathrm{Al}_{1-\mathrm{x}} \mathrm{N}$ and of $\mathrm{Ga}_{\mathrm{x}} \mathrm{Al}_{1-\mathrm{x}} \mathrm{N}$ with error not greater than $7.5 \%$, and the corresponding tetrahedral edge $l_{0}$ in the electron metric system. However this conclusion is made on the basis of the independent binary alloys that are possible binary constituents. The authors assume that a detail investigation may give constant value of $|\mathrm{Z}|$ without theoretical error.

The purpose of the electron metric system in this paper is to define the symmetry of the multinary crystal in term of crystal lattice and the corresponding symmetries of both the electron wave function and the potential function. Further development of this metric system and its application in the quantum mechanics of solids goes beyond the scope of this paper and it is subject of other author's papers.

\section{Electron wave vector and electron states in multinary crystal}

The change of the metric system requires a new approach in the determination of the electron wave vector because the electron wave length has to be determined in the corresponding metric system. This problem will be solved on the basis of the following assumptions:

i) The quasi-elementary tetrahedral cell is electro-neutral;

ii) The electrons belonging to both the conduction band and the valence band have energies $E$ greater than the potential energy $U$ of the nuclei of certain quasi-elementary tetrahedral cell;

Using these assumptions and the result in [9] one can write $\left(k_{x i}\right.$ and $k_{l}$ are the electron wave vectors in the external metric system and in the electron metric system respectively, and $\mathrm{n}$ is positive integer number):

- for the external metric system

$$
(1 / \hbar) \int_{x_{A}}^{x_{B}}\left\{2 m\left[\mathrm{E}-\mathrm{U}\left(x_{i}\right)\right]\right\}^{1 / 2} d x_{i}=\left|x_{B}-x_{A}\right| k_{x i}=\mathrm{n} \pi
$$

$\left(\left|x_{B}-x_{A}\right|\right.$ is tetrahedral edge)

- for the electron metric system

$$
(1 / \hbar) \int_{0}^{l_{0}}\{2 m[\mathrm{E}-\mathrm{U}(l)]\}^{1 / 2} d l=l_{0} k_{l}=\mathrm{n} \pi
$$

The equations (9) and (10) give

$$
\left|x_{B}-x_{A}\right| k_{x i}=l_{0} k_{l}=\mathrm{n} \pi
$$

As a matter of fact the distance $\left|x_{B}-x_{A}\right|$ determines the length of the tetrahedral edge of certain quasi-elementary cell in the external metric system (the tetrahedral edges of different quasi-elementary cells having $|Z|$ have different lengths in the external metric system, and equal lengths in the electron metric system). The equalities (11) have important meaning - they are basis of the following conclusions: 
1) The electron wave length $\lambda_{l}$ in the electron metric system stays unchanged when the electron is moving through different quasi-elementary tetrahedral cells and

$$
\lambda_{l}=2 l_{0} / \mathrm{n}
$$

2) The electron wave length $\lambda_{x i}$ in the external metric system changes when the electron is moving through different quasi-elementary tetrahedral cells.

3) The Bloch's theorem is satisfied in the electron metric system.

4) The number of electron states remains unchanged in different metric systems. (It means one can determine the electron states in the electron metric system and they give the corresponding states in the external metric system.)

5) Considering that a sub-lattice of the multinary crystal is built by different sort of atoms one must expect that the electron energy corresponding to certain electron state depends on the quasi-elementary cell, i.e. the formula derived in [10] is valid.

$$
\mathrm{E}(\boldsymbol{r})=\sum_{\mathbf{q}} \delta\left(\boldsymbol{r}-\boldsymbol{R}_{\boldsymbol{q}}\right) \mathrm{E}(\mathbf{q})
$$

where $\mathrm{E}(\mathbf{q})$ is electron energy in quasi-elementary cell having radius-vector $\boldsymbol{R}_{\boldsymbol{q}}$, and $\boldsymbol{r}$ is radius-vector. Both $\boldsymbol{R}_{\boldsymbol{q}}$ and $\boldsymbol{r}$ can be determined in both metric systems, however the application of the electron metric system in calculation of the Hamiltonian matrix elements goes beyond the scope of this paper and the calculations of the corresponding matrix elements will be done in the external metric system furthermore according to the conclusion 4), which is given above, the determination of the electron states can be made in the electron metric system, and the calculation of the corresponding electron energies can be done in the external metric system (conclusion 5).

Calculations of LCAO electron energies for the electron state $\mathrm{k}=0$ (i.e. point $\Gamma$ of the electron band structure) will be presented for $\operatorname{In}_{\mathrm{x}} \mathrm{Al}_{1-\mathrm{x}} \mathrm{N}$. (Details of these calculations are given in $[5,10]$.) Each type of quasi-elementary cell forms sector $v$ of the corresponding electron band structure $(v=1,2,3,4,5)$. In terms of both the optical absorption and the photoluminescence the energy band gap of $\mathrm{In}_{\mathrm{x}} \mathrm{Al}_{1-\mathrm{x}} \mathrm{N}$ has to be determined as energy differences between $\Gamma_{c l}^{\mathrm{v}}$ (the bottom of the conduction band of sector $\mathrm{U}$ ) and $\Gamma^{\mathrm{v}}{ }_{v 15}$ (the top of the valence band of sector v). The results of the calculations are given in Fig.2 for $\operatorname{In}_{\mathrm{x}} \mathrm{Al}_{1-\mathrm{x}} \mathrm{N}$. The energy levels $\Gamma_{c l}^{\mathrm{v}}$ and $\Gamma^{\mathrm{v}}{ }_{v 15}$ are determined by taking the energy of the vacuum as being equal to zero. The energy difference $\mathrm{E}_{\mathrm{g}}^{\mathrm{v}}=\left(\Gamma_{c l}^{\mathrm{v}}-\Gamma^{\mathrm{v}}{ }_{v 15}\right)$ gives the energy band gap of sector $v$. The shifts of the boundaries of the energy band gaps in Fig.2, and the corresponding energy intervals are due to defects in the crystal lattices of $\mathrm{In}_{\mathrm{x}} \mathrm{Al}_{1-\mathrm{x}} \mathrm{N}$. The nature of these shifts is different from the nature of the shifts of the boundaries of the energy band gap described in $[11,12]$. The same approach is used for determination of the energy states in $\operatorname{In}_{x} \mathrm{Ga}_{1-\mathrm{x}} \mathrm{N}$ [10], in $\mathrm{InO}_{\mathrm{y}} \mathrm{N}_{1-\mathrm{y}}$ [5] and in non-stoichiometric InN [13]. 


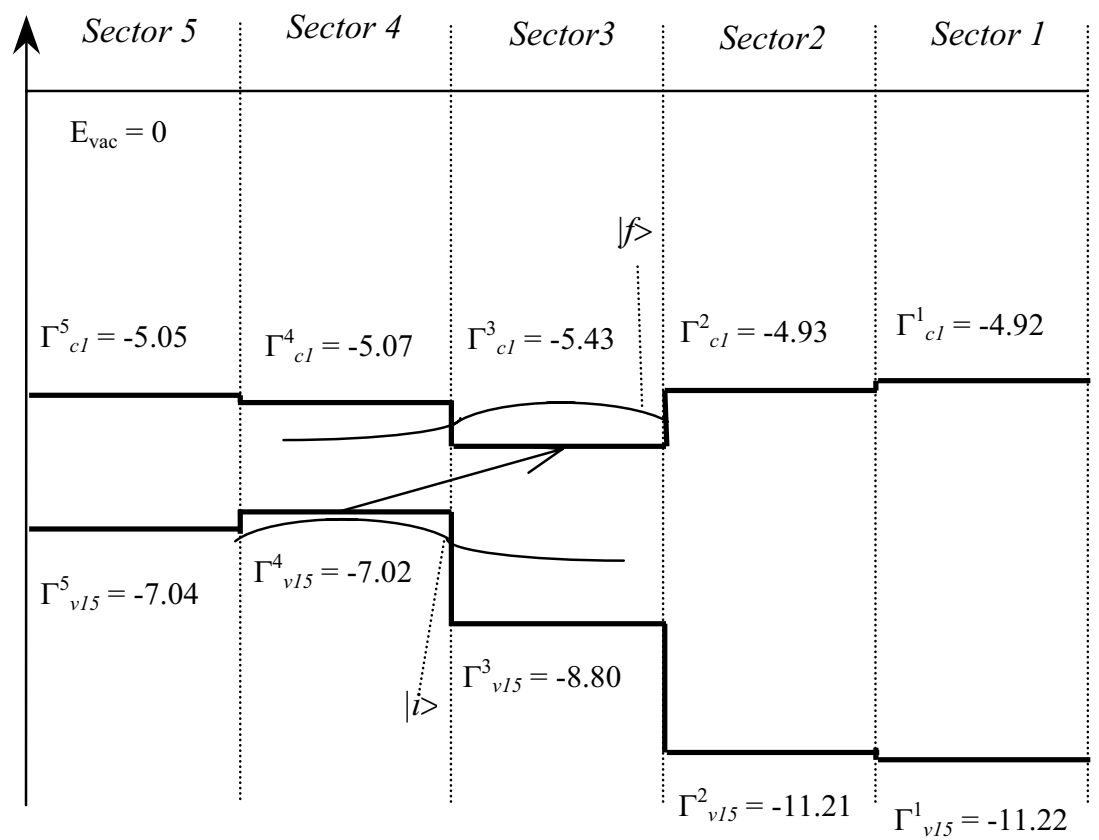

Figure 2: The energy band gap of $\operatorname{In}_{\mathrm{x}} \mathrm{Al}_{1-\mathrm{x}} \mathrm{N}$. The energies $\Gamma_{c l}^{\mathrm{v}}$ and $\Gamma_{v 15}^{\mathrm{v}}$ are shown (the sectors are $v=1,2,3,4,5)$. The shapes of parts of the electron wave functions corresponding to both the initial $\mid i>$ and final state $\mid f>$ are given and the allowed optical absorption transition is shown.

\section{Electron and optical phenomena in semiconductor compound alloys related to InN}

\subsection{Excitons of the structure in $\operatorname{In}_{x} \mathrm{Al}_{1-\mathrm{x}} \mathrm{N}$, in $\operatorname{In}_{x} \mathrm{Ga}_{1-\mathrm{x}} \mathrm{N}$, and in $\operatorname{InO}_{y} \mathrm{~N}_{1-\mathrm{y}}$}

An exciton of the structure in $\operatorname{In}_{\mathrm{x}} \mathrm{Al}_{1-\mathrm{x}} \mathrm{N}$ is formed by an electron occupying state $\Gamma^{3}{ }_{c l}$ and a hole occupying state $\Gamma^{4}{ }_{v 15}$ (Fig. 2). This exciton state $\Gamma^{3}{ }_{c l} \leftrightarrow \Gamma^{4}{ }_{v 15}$ is defined as the ground exciton state for this type of exciton in $\operatorname{In}_{\mathrm{x}} \mathrm{Al}_{1-\mathrm{x}} \mathrm{N}$. Using the method given in [10] the hydrogen like energy level $E_{n}$ for the ground state $(\mathrm{n}=1)$ is found to depend on the ratio between neighbouring Al cationic and neighbouring In cationic surrounding the quasi-elementary cells of sectors 3 and 4 of Fig.2. It is found $E_{n}$ varies in the interval $0.765-0.778 \mathrm{eV}$ and these energies are in agreement with the optical transitions corresponding to the experimental photoluminescence spectra of samples containing interface layers $\mathrm{In}_{\mathrm{x}} \mathrm{Al}_{1-\mathrm{x}} \mathrm{N}-\sim 0.77 \mathrm{eV}$ reported in [2] and $\sim 0.8 \mathrm{eV}$ given in [3]. As a mater of fact $\mathrm{E}_{\mathrm{n}}$ determines the optical transitions connected with photon radiation due to annihilations between the electrons and the holes belonging to the exciton $\Gamma^{3}{ }_{c l}$ $\leftrightarrow \Gamma^{4}{ }_{v 15}$ in $\operatorname{In}_{\mathrm{x}} \mathrm{Al}_{1-\mathrm{x}} \mathrm{N}$. Excitons of the structure in $\operatorname{In}_{\mathrm{x}} \mathrm{Ga}_{1-\mathrm{x}} \mathrm{N}$ are investigated in 
details in [10]. It is found that the hydrogen like energy level $E_{n}$ varies over the interval $0.50-0.82 \mathrm{eV}$ and these energies are close to the experimental results about the photoluminescence spectra of In-rich regions of $\operatorname{In}_{\mathrm{x}} \mathrm{Ga}_{1-\mathrm{x}} \mathrm{N}$ reported in [14-16]. The same type of exciton in $\mathrm{InO}_{\mathrm{y}} \mathrm{N}_{1-\mathrm{y}}$ is investigated in details in [5]. It is found that the hydrogen like energy level $\mathrm{E}_{\mathrm{n}}$ varies over the interval $0.84-$ $1.01 \mathrm{eV}$, and that it determines the optical transitions connected with photon radiation due to annihilations between the electrons and the holes belonging to these excitons in $\mathrm{InO}_{\mathrm{y}} \mathrm{N}_{1-\mathrm{y}}$. The photoluminescence rates in $\operatorname{In}_{\mathrm{x}} \mathrm{Al}_{1-\mathrm{x}} \mathrm{N}$, in $\mathrm{In}_{\mathrm{x}} \mathrm{Ga}_{1-\mathrm{x}} \mathrm{N}$ and in $\mathrm{InO}_{\mathrm{y}} \mathrm{N}_{1-\mathrm{y}}$ depend on the concentration of the corresponding excitons of the structure, and this in turn depends on the technological circumstances forming this alloys.

\subsection{Tunnel optical absorptions in semiconductors related to InN}

The tunnel optical absorption in $\operatorname{In}_{x} \mathrm{Al}_{1-\mathrm{x}} \mathrm{N}$, in $\operatorname{InO}_{\mathrm{y}} \mathrm{N}_{1-\mathrm{y}}$, in $\operatorname{In}_{\mathrm{x}} \mathrm{Ga}_{1-\mathrm{x}} \mathrm{N}$ is investigated in details in [5]. The basis of this phenomenon is the overlapping between the electron wave function $\mid i>$ of the initial electron state and the electron wave function of the final electron state $\mid f>$ in term of optical transition. Part of the graphics of figure 2 provides the electron wave functions of the initial state $\mid i>$ and of the final state $\mid f>$ for $\operatorname{In}_{\mathrm{x}} \mathrm{Al}_{1-\mathrm{x}} \mathrm{N}$ (it is important to note that the state $i>$ is an electron state, it is not a hole state). It is found [5] the lengths (in the one-dimensional case) of the regions where the matrix element of the optical absorption has non-zero values due to the penetrations of the electron wave functions into the barriers. The length for $\operatorname{In}_{x} \mathrm{Al}_{1-\mathrm{x}} \mathrm{N}$ is determined to vary in the interval 4.70 - 4.72 Angstrom depending on the number of In and Al atoms

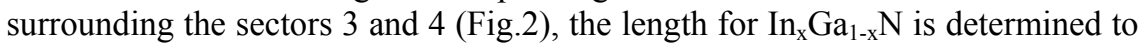
vary in the interval $4.61-4.64$ Angstrom, and the length for $\mathrm{InO}_{\mathrm{y}} \mathrm{N}_{1-\mathrm{y}}$ is found to vary in the interval $1.98-2.00$ Angstrom. The conclusion is made [5] that the optical absorption transitions $\Gamma_{v 15}^{4} \rightarrow \Gamma_{c l}^{3}$ for $\operatorname{In}_{\mathrm{x}} \mathrm{Al}_{1-\mathrm{x}} \mathrm{N}$ and $\Gamma_{v 15}^{3} \rightarrow \Gamma_{c l}^{4}$ for $\mathrm{In}_{\mathrm{x}} \mathrm{Ga}_{1-\mathrm{x}} \mathrm{N}$ are allowed and they give the optical absorption edges and the corresponding energy band gaps (for $\operatorname{In}_{\mathrm{x}} \mathrm{Al}_{1-\mathrm{x}} \mathrm{N} \mathrm{E}_{\mathrm{g}}=\Gamma_{c l^{3}}^{3} \Gamma^{4}{ }_{v 15}$ and for $\operatorname{In}_{\mathrm{x}} \mathrm{Ga}_{1-\mathrm{x}} \mathrm{N}$ $\left.\mathrm{E}_{\mathrm{g}}=\Gamma_{c l}^{4}-\Gamma^{3}{ }_{v 15}\right)$. The similar conclusions are made for $\mathrm{InO}_{\mathrm{y}} \mathrm{N}_{1-\mathrm{y}}$ as well. It is important to note that if the distances between the corresponding quasielementary cells (forming the sectors) are longer than the lengths of the regions determined above the optical absorption transitions given above will not be allowed). The optical absorption rates depend on the number of $\Gamma_{v 15}^{v} \rightarrow \Gamma_{c 1}^{\xi}$ pairs for $\mathrm{In}_{\mathrm{x}} \mathrm{Al}_{1-\mathrm{x}} \mathrm{N}$, for $\mathrm{InO}_{\mathrm{y}} \mathrm{N}_{1-\mathrm{y}}$ and for $\mathrm{In}_{\mathrm{x}} \mathrm{Ga}_{1-\mathrm{x}} \mathrm{N}$ in the corresponding primitive super-cells that are connected with the technological circumstances (growth conditions) forming the layers $\operatorname{In}_{x} \mathrm{Al}_{1-\mathrm{x}} \mathrm{N}, \mathrm{InO}_{\mathrm{y}} \mathrm{N}_{1-\mathrm{y}}$ and $\operatorname{In}_{\mathrm{x}} \mathrm{Ga}_{1-\mathrm{x}} \mathrm{N}$. The energy $\mathrm{E}_{\mathrm{g}}$ for $\operatorname{In}_{\mathrm{x}} \mathrm{Al}_{1-\mathrm{x}} \mathrm{N}$ is found to vary in the interval $1.58-1.62 \mathrm{eV}$, the energy $\mathrm{E}_{\mathrm{g}}$ for $\mathrm{InO}_{\mathrm{y}} \mathrm{N}_{1-\mathrm{y}}$ is found to have a small variation around $1.19 \mathrm{eV}$, and the energy $\mathrm{E}_{\mathrm{g}}$ for $\mathrm{In}_{\mathrm{x}} \mathrm{Ga}_{1-\mathrm{x}} \mathrm{N}$ is found to vary in the interval $1.40-1.56 \mathrm{eV}$. These energies (especially the energy $\mathrm{E}_{\mathrm{g}} \sim 1.19 \mathrm{eV}$ for $\mathrm{InO}_{\mathrm{y}} \mathrm{N}_{1-\mathrm{y}}$ ) are close to the optical absorption edge that shows the optical transmission data for the Ioffe sample W431. The tunnel optical absorption in non-stoichiometric InN:In is investigated in details in [13]. It determines energy band gap $\mathrm{E}_{\mathrm{g}}=0.2 \mathrm{eV}$. (However the single substitutions In atom on $\mathrm{N}$ site do not reduce the energy band gap to zero.) 


\section{Conclusion}

The development of the electron metric system and its application in calculations of the electron band structure of multinary crystal has an important impact over the investigation of the disordered atomic systems. In fact, the calculations of the Hamiltonian matrix elements can be done in this metric system and the authors believe these calculations to become easier and more accurate. The observed phenomena excitons of the structure and tunnel optical absorption can be used in design of semiconductor devices on $\mathrm{InN}$ and related alloys.

\section{References}

[1] K.S.A. Butcher, M. Wintrebert-Fouquet, K.E. Prince and T.L. Tansley, Materials Research Society Symposium Proceeding 743, 707 (2003).

[2] J. Wu, W. Walukiewicz, K. M. Yu, J. W. Ager III, E. E. Haller, H. Lu, W. J. Schaff, Y. Saito, Y. Nanishi, Applied Physics Letters 80, 3967 (2002).

[3] V. Yu. Davydov, A. A. Klochikhin, V. V. Emtsev, S. V. Ivanov, V. A. Vekchin, F. Bechsted, J. Furthmuller, J. Aderhold, J. Graul, A. V. Mudryi, H. Harima, A. Hashimoto, Y. Yamamoto, E. E. Haller, Physica Status Solidi. (b) 234, 787 (2002).

[4] T.L. Tansley, presentation at the First Internat. InN Workshop, Fremantle, Australia, Nov. 2003.

[5] D. Alexandrov, K.S.A. Butcher, M. Wintrebert-Fouquet, Journal of Crystal Growth 269, 77 (2004)

[6] F. London, Zeit. F. Phys. 42, 375 (1927)

[7] L. O'Raifeartaigh, The Dawning of Gauge Theory, (Princeton university press, Princeton, 1997), part I

[8] W.A. Harrison, Electronic Structure and the Properties of Solids, Dover Publ. Inc, (1989)

[9] A.S. Davydov, Quantum Mechanics (Pergamon press, Don Mills, 1965)

[10] D. Alexandrov, Journal of Crystal Growth, 246, 325 (2002)

[11] H. Fritzsche, Journal of Non-Crystal Solids, 6, 49 (1971)

[12] A. Efros, B. Shklovskii, Electronic Properties of Doped Semiconductors (Springer-Verlag, Berlin - Heidelberg 1984)

[13] D. Alexandrov, K.S.A. Butcher, T. Tansley, Journal of Crystal Growth 288, 261 (2006).

[14] V. Yu. Davydov, A. A. Klochikhin et al., Phys. Stat. Sol. (b), 229,1 (2002)

[15] V. Yu. Davydov, A. A. Klochikhin et al., Phys. Stat. Sol. (b), 230, 4 (2002)

[16] V. Yu. Davydov, A. A. Klochikhin et al., International Workshop on Nitride Semiconductors, 22 - 25 July 2002, Aachen, Germany, p.133 (2002) 